\title{
Massic Activity Ratios of the NBS/NIST Tritiated-Water Standards Issued Between 1954 and 1999
}

\section{L. Lucas}

National Institute of Standards and Technology, Gaithersburg, MD 20899-8462 U.S.A larry.lucas@nist.gov
As part of the preparation and calibration of three new National Institute of Standards and Technology (NIST) tritiated-water radioactivity Standard Reference Materials (SRMs), the massic-activity (activity of the sample divided by the mass of the sample) ratios of all of the available NBS/ NIST tritiated-water SRMs issued between 1954 and 1999 were measured using liquid-scintillation (LS) counting. Four of the tritiated-water standards (SRMs 4361, 4926B, 4927C, and 4927D) were not available for measurement. All of the other tritiated-water standards (SRMs 4361B, 4361C, 4926, 4926C, 4926D, 4926E, 4927. 4927B, 4927E, and 4927F) were available, having been stored in flame-sealed glass ampoules. Where possible, massic- activity ratios measured by liquid-scintillation counting are compared with massicactivity ratios calculated from gravimetric dilution factors. The agreement is well within the stated uncertainties. For two of the tritiated-water standards that were not available for measurement (SRMs 4361 and 4926B), massic-activity ratios calculated from gravimetric dilution factors are available.

Key words: hydrogen-3; massic activity; NBS; NIST; standards; tritiated water; tritium.

Accepted: July 27, 2000

Available online: http://www.nist.gov/jres

\section{Introduction}

The National Institute of Standards and Technology (NIST), previously the National Bureau of Standards (NBS), has issued solution standards of tritiated water since 1954. A chronology is given in Table 1. The original solutions, NBS Standard No. 4926 and NBS Standard No. 4927, were calibrated using calorimetry [1]. In 1961, the massic activity (activity of the sample divided by the mass of the sample) of NBS Standard No. 4927 was measured in the (then) new NBS length-compensated internal gas proportional counters [2] and a revised certificate was issued. The massic activities of NBS Standard No. 4927 and of the new Standard Reference Material (SRM) 4927B were measured in 1978 using the same counters [3]. The massic activities of SRM
4927E and of NBS Standard No. 4927 were measured in 1998 and 1999, respectively, in the same counters [4].

As part of the preparation and calibration of three new NIST tritiated-water radioactivity SRMs, the massic-activity ratios of all of the available NBS/NIST tritiated-water SRMs issued between 1954 and 1999, and of samples of the Level 1 and Level 3 tritiated-water standards produced by the National Physical Laboratory (NPL) in 1996, were measured using liquid-scintillation (LS) counting. The results for the NPL samples are reported elsewhere [4]. Four of the tritiated-water standards (SRMs 4361, 4926B, 4927C, and 4927D) were not available for measurement. All of the other tritiatedwater standards (SRMs 4361B, 4361C, 4926, 4926C, 
Table 1. Chronology of the NBS/NIST tritiated-water standards issued between 1954 and 1999

\begin{tabular}{|c|c|c|c|c|}
\hline $\begin{array}{l}\text { Year } \\
\text { Issued }\end{array}$ & $\begin{array}{l}\text { High-level } \\
\text { standard }\end{array}$ & $\begin{array}{l}\text { Medium-level } \\
\text { standard }\end{array}$ & $\begin{array}{l}\text { Low-level } \\
\text { standard }\end{array}$ & Comments \\
\hline 1954 & NBS 4927 & NBS 4926 & & $\begin{array}{l}\text { Calibrated by calorimetry. NBS } 4926 \text { is } \\
\text { a quantitative dilution of NBS } 4927 \text {. }\end{array}$ \\
\hline 1961 & NBS 4927 & NBS 4926 & & $\begin{array}{l}\text { Recalibrated by gas counting. Revised } \\
\text { certificate issued. }\end{array}$ \\
\hline 1965 & & & & $\begin{array}{l}\text { New standards are now called NBS } \\
\text { Standard Reference Materials (SRMs). }\end{array}$ \\
\hline 1977 & & SRM 4926B & & $\begin{array}{l}\text { SRM } 4926 \text { B is a quantitative dilution of } \\
\text { NBS } 4927 .\end{array}$ \\
\hline 1979 & SRM 4927B & SRM 4926C & & $\begin{array}{l}\text { Calibrated by gas counting. SRM } \\
\text { 4926C is a quantitative dilution of SRM } \\
\text { 4927B. }\end{array}$ \\
\hline 1981 & & & SRM 4361 & $\begin{array}{l}\text { SRM } 4361 \text { is a quantitative dilution of } \\
\text { NBS } 4926 .\end{array}$ \\
\hline 1985 & SRM 4927C & & & a \\
\hline 1987 & & & SRM 4361B & $\begin{array}{l}\text { SRM 4361B is a quantitative dilution of } \\
\text { SRM 4926C. }\end{array}$ \\
\hline 1989 & SRM 4927D & SRM 4926D & & $\begin{array}{l}\text { SRM } 4926 \mathrm{D} \text { is not a quantitative } \\
\text { dilution of SRM 4927D. }{ }^{\text {a }}\end{array}$ \\
\hline 1991 & SRM 4927E & & & 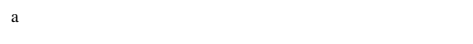 \\
\hline 1999 & SRM 4927F & SRM 4926E & SRM 4361C & $\begin{array}{l}\text { Calibrated by gas counting. SRM } \\
4926 \mathrm{E} \text { is a quantitative dilution of SRM } \\
\text { 4927F. SRM } 4361 \mathrm{C} \text { is a quantitative } \\
\text { dilution of SRM } 4926 \mathrm{E} \text {. }\end{array}$ \\
\hline
\end{tabular}

a The massic activities on the Certificates for SRMs 4927C, 4927D, 4926D, and 4927E were obtained using liquid-scintillation counting to determine the massic-activity ratios to SRM 4927B.

4926D, 4926E, 4927, 4927B, 4927E, and 4927F) were available, having been stored in flame-sealed glass ampoules. Where possible, massic-activity ratios measured by liquid-scintillation counting are compared with massic-activity ratios calculated from gravimetric dilution factors. The agreement is well within the stated uncertainties. For two of the tritiated-water standards that were not available for measurement (SRMS 4361 and 4926B), massic-activity ratios calculated from gravimetric dilution factors are available.

\section{Liquid-Scintillation Measurements}

As part of the preparation and calibration of a new series of tritiated-water SRMs (4361C, 4926E, and 4927F), five batches of liquid-scintillation samples were prepared during 1998 and 1999. The first batch compared the massic activities of the new medium-level (SRM 4926E) and the new and old low-level (4361C and 4361B) tritiated-water SRMs. The second, third, fourth, and fifth batches compared the massic activities of all of the available high-level $(4927,4927 \mathrm{~B}, 4927 \mathrm{E}$, and 4927F) and medium-level (4926, 4926C, 4926D, and 4926E) tritiated-water SRMs, and of several samples of the Level 1 and Level 3 tritiated-water standards produced by NPL in 1996. For most of the SRMs, several ampoules of the SRM were sampled. Several independent dilutions of each high-level SRM or standard were made so that all of the LS vials had approximately the same count rate. This minimized any uncertainty due to dead time variation.

For each batch, four LS vials were prepared from each sample (ampoule or dilution) of each SRM or NPL standard. Each LS vial consisted of $10 \mathrm{~mL}$ of Beckman ReadySafe cocktail in a Beckman $18 \mathrm{~mL}$ polyethylene vial $^{1}$. Each of the four LS vials was quenched with a different (but reproducible) amount of distilled water. The range of quench corresponded to a change in average pulse height of about $20 \%$. Approximately the same mass of tritiated water was weighed into each of the LS vials. The LS vials were then counted in one of two commercial LS counters, a Beckman LS7800 or a Packard 2500TR. Both counters use an external gamma-ray source to determine a quench indicating parameter $(Q I P)$. The counting window was set for tritium (0 keV to $18.6 \mathrm{keV})$. One counting cycle consisted of sequentially counting each LS vial in a given batch for $15 \mathrm{~min}$. One run consisted of this counting

\footnotetext{
${ }^{1}$ Certain commercial equipment, instruments, or materials are identified in this paper to foster understanding. Such identification does not imply recommendation or endorsement by the National Institute of Standards and Technology, nor does it imply that the materials or equipment identified are necessarily the best available for the purpose.
} 
cycle repeated 10 times. The data for each run were analyzed separately. The LS vials were then counted for 10 cycles in the other LS counter. This was repeated twice, so that the total count time for each LS vial was 600 minutes ( 2 counters times 2 runs per counter times 10 cycles per run times $15 \mathrm{~min}$. per cycle) over a period of about 4 weeks.

For each run, a second-order polynomial $(y=$ massic count rate, $x=Q I P$ ) was fitted to the data (typically 40 points) for each set of four LS vials using a least-squares technique. Three values of the QIP were selected (low, middle, and high) that could be used for all of the data in a given run. The massic count rate for each sample, at each of the three $Q I P$ values, was then calculated using the polynomial. For any two samples, three ratios of the massic count rate (one at each of the selected $Q I P$ values) were obtained. The ratio of massic activities of any two samples in a given run was taken to be the average of these three massic count rate ratios. The standard deviation of the mean of the three ratios was used as an indication of the uncertainty associated with the ratio.

The final ratio of the massic activities of any two samples was taken to be the average of the ratios from all of the runs in which the two samples were intercompared. Because the liquid-scintillation samples had been so carefully matched with regard to other parameters, the relative standard deviation of the mean was used as the best estimate of the relative standard uncertainty associated with the final ratio.

\section{Discussion of Results}

Table 2 gives the massic-activity ratios for the highlevel and medium-level SRMs. Table 3 gives the massicactivity ratios for the medium-level and low-level SRMs. For some of the SRMs, massic-activity ratios calculated from gravimetric dilution factors are available. These are given in Table 4 and, where possible, are compared with the massic-activity ratios measured by liquid-scintillation counting. It can be seen that the agreement is very good. This suggests that the massic activity ratios for SRM 4927 / SRM 4926B and SRM 4926 / SRM 4361, calculated from the gravimetric dilution factors, are probably also reliable to within the estimated uncertainty.

Table 2. Massic-activity ratios measured by liquid-scintillation counting for NBS/NIST tritiated-water standards issued between 1954 and 1999 : high-level and medium-level standards. Each ratio is the massic activity of the SRM listed at the top of the table divided by the massic activity of the SRM listed on the left side of the table. The relative standard uncertainties of the ratios are shown as percentages. The number of sets of liquid-scintillation measurements are shown in parentheses

\begin{tabular}{|c|c|c|c|c|c|c|}
\hline $\begin{array}{c}\text { Ratio } \\
\text { (Top/Side) }\end{array}$ & $\begin{array}{c}\text { SRM } \\
4927 \mathrm{~F}\end{array}$ & $\begin{array}{c}\text { SRM } \\
4927 \mathrm{E}\end{array}$ & $\begin{array}{c}\text { SRM } \\
\text { 4927D }\end{array}$ & $\begin{array}{l}\text { SRM } \\
4927 \mathrm{C}\end{array}$ & $\begin{array}{c}\text { SRM } \\
\text { 4927B }\end{array}$ & $\begin{array}{l}\text { SRM } \\
4927\end{array}$ \\
\hline $\begin{array}{c}\text { SRM } \\
4927 \mathrm{~F}\end{array}$ & 1.00000 & & & & & \\
\hline $\begin{array}{c}\text { SRM } \\
4927 \mathrm{E}\end{array}$ & $\begin{array}{l}1.71524 \\
0.052 \%(7)\end{array}$ & 1.00000 & & & & \\
\hline $\begin{array}{c}\text { SRM } \\
\text { 4927D }\end{array}$ & & & 1.00000 & & & \\
\hline $\begin{array}{c}\text { SRM } \\
4927 C\end{array}$ & & & & 1.00000 & & \\
\hline $\begin{array}{c}\text { SRM } \\
\text { 4927B }\end{array}$ & $\begin{array}{l}2.84583 \\
0.064 \%(7)\end{array}$ & $\begin{array}{l}1.65892 \\
0.036 \% \text { (11) }\end{array}$ & & & 1.00000 & \\
\hline $\begin{array}{l}\text { SRM } \\
4927\end{array}$ & $\begin{array}{l}5.75385 \\
0.056 \% \text { (4) }\end{array}$ & $\begin{array}{l}3.35603 \\
0.046 \%(8)\end{array}$ & & & $\begin{array}{l}2.02372 \\
0.016 \%(12)\end{array}$ & 1.00000 \\
\hline $\begin{array}{c}\text { SRM } \\
4926 \mathrm{E}\end{array}$ & $\begin{array}{l}125.959^{\mathrm{a}} \\
0.041 \%(7)\end{array}$ & $\begin{array}{l}73.4585 \\
0.013 \%(7)\end{array}$ & & & $\begin{array}{l}44.2898 \\
0.071 \%(11)\end{array}$ & $\begin{array}{l}21.9070 \\
0.005 \%(8)\end{array}$ \\
\hline $\begin{array}{l}\text { SRM } \\
4926 \mathrm{D}\end{array}$ & $\begin{array}{l}369.546 \\
0.086 \% \text { (7) }\end{array}$ & $\begin{array}{l}215.450 \\
0.034 \% \text { (7) }\end{array}$ & & & $\begin{array}{l}129.939 \\
0.107 \% \text { (11) }\end{array}$ & $\begin{array}{l}64.2939 \\
0.020 \%(8)\end{array}$ \\
\hline $\begin{array}{l}\text { SRM } \\
4926 C\end{array}$ & $\begin{array}{l}576.758 \\
0.066 \% \text { (4) }\end{array}$ & $\begin{array}{l}336.082 \\
0.049 \%\end{array}$ & & & $\begin{array}{l}202.760^{\mathrm{a}} \\
0.047 \%(8)\end{array}$ & $\begin{array}{l}100.184 \\
0.055 \%(8)\end{array}$ \\
\hline $\begin{array}{c}\text { SRM } \\
4926 B\end{array}$ & & & & & & a \\
\hline $\begin{array}{l}\text { SRM } \\
4926\end{array}$ & $\begin{array}{l}576.398 \\
0.049 \%\end{array}$ & $\begin{array}{l}336.261 \\
0.058 \%(8)\end{array}$ & & & $\begin{array}{l}202.778^{\mathrm{a}} \\
0.029 \%(12)\end{array}$ & $\begin{array}{l}100.201^{\mathrm{a}} \\
0.023 \%(12)\end{array}$ \\
\hline
\end{tabular}

\footnotetext{
${ }^{\text {a }}$ The massic-activity ratio calculated from the gravimetric dilution factor is available; see Table 4 .
} 
Table 3. Massic-activity ratios measured by liquid-scintillation counting for NBS/NIST tritiated-water standards issued between 1954 and 1999 : medium-level and low-level standards. Each ratio is the massic activity of the SRM listed at the top of the table divided by the massic activity of the SRM listed on the left side of the table. The relative standard uncertainties of the ratios are shown as percentages. The number of sets of liquid-scintillation measurements are shown in parentheses

\begin{tabular}{|c|c|c|c|c|c|c|c|}
\hline $\begin{array}{c}\text { Ratio } \\
\text { (Top/Side) }\end{array}$ & $\begin{array}{c}\text { SRM } \\
4926 \mathrm{E}\end{array}$ & $\begin{array}{c}\text { SRM } \\
4926 \mathrm{D}\end{array}$ & $\begin{array}{c}\text { SRM } \\
4926 C\end{array}$ & $\begin{array}{c}\text { SRM } \\
4926 B\end{array}$ & $\begin{array}{l}\text { SRM } \\
4926\end{array}$ & $\begin{array}{l}\text { SRM } \\
4361 C\end{array}$ & $\begin{array}{c}\text { SRM } \\
4361 B\end{array}$ \\
\hline $\begin{array}{c}\text { SRM } \\
4926 \mathrm{E}\end{array}$ & 1.00000 & & & & & & \\
\hline $\begin{array}{l}\text { SRM } \\
4926 \mathrm{D}\end{array}$ & $\begin{array}{l}2.93382 \\
0.038 \%\end{array}$ & 1.00000 & & & & & \\
\hline $\begin{array}{l}\text { SRM } \\
4926 \mathrm{C}\end{array}$ & $\begin{array}{l}4.57316 \\
0.050 \%\end{array}$ & $\begin{array}{l}1.55823 \\
0.074 \%(8)\end{array}$ & 1.00000 & & & & \\
\hline $\begin{array}{c}\text { SRM } \\
4926 B\end{array}$ & & & & 1.00000 & & & \\
\hline $\begin{array}{l}\text { SRM } \\
4926\end{array}$ & $\begin{array}{l}4.57357 \\
0.022 \%(8)\end{array}$ & $\begin{array}{l}1.55837 \\
0.003 \%(8)\end{array}$ & $\begin{array}{l}1.00019 \\
0.042 \%(8)\end{array}$ & & 1.00000 & & \\
\hline $\begin{array}{c}\text { SRM } \\
4361 C\end{array}$ & $\begin{array}{l}2504.65^{\mathrm{a}} \\
0.17 \% \text { (4) }\end{array}$ & & & & & 1.00000 & \\
\hline $\begin{array}{c}\text { SRM } \\
4361 B\end{array}$ & $\begin{array}{l}8404.44^{\mathrm{b}} \\
0.58 \% \text { (4) }\end{array}$ & & a & & & $\begin{array}{l}3.35548^{\mathrm{b}} \\
0.53 \%(4)\end{array}$ & 1.00000 \\
\hline $\begin{array}{l}\text { SRM } \\
4361\end{array}$ & & & & & a & & \\
\hline
\end{tabular}

${ }^{a}$ The massic-activity ratio calculated from the gravimetric dilution factor is available; see Table 4.

${ }^{\mathrm{b}}$ The uncertainty associated with this measurement is much larger than for most of the liquid-scintillation measurements because of the very low massic activity of SRM 4361B at the time of measurement.

Table 4. Massic-activity ratios measured by liquid-scintillation counting compared to massic-activity ratios calculated from gravimetric dilution factors. The relative standard uncertainties of the ratios are shown as percentages. The number of sets of liquid-scintillation measurements are shown in parentheses

\begin{tabular}{llll}
\hline $\begin{array}{c}\text { Massic-activity } \\
\text { Ratio }\end{array}$ & $\begin{array}{c}\text { From the } \\
\text { dilution factor }\end{array}$ & $\begin{array}{c}\text { From liquid- } \\
\text { scintillation }\end{array}$ & Difference \\
\hline SRM 4927F / & 125.880 & 125.959 & $+0.06 \%$ \\
SRM 4926E & $\approx 0.05 \%$ & $0.041 \%(7)$ & \\
SRM 4927B / & 202.905 & 202.760 & $-0.07 \%$ \\
SRM 4926C & $\approx 0.05 \%$ & $0.047 \%(8)$ & \\
SRM 4927 / & 100.236 & & \\
SRM 4926B & $\approx 0.06 \%$ & & $+0.05 \%$ \\
SRM 4927 / & 100.148 & 100.201 & \\
SRM 4926 & $\approx 0.05 \%$ & $0.023 \%(12)$ & \\
SRM 4926E / & 2507.56 & 2504.65 & $+0.01 \%$ \\
SRM 4361C & $\approx 0.12 \%$ & $0.17 \%(4)$ & \\
SRM 4926C / & 1837.54 & $1837.78^{\mathrm{a}}$ & \\
SRM 4361B & $\approx 0.15 \%$ & $0.58 \%(4)$ & \\
SRM 4926 / & 2596.08 & & \\
SRM 4361 & $\approx 0.20 \%$ & & \\
& & & \\
\hline
\end{tabular}

${ }^{a}$ Calculated as (SRM 4926E / SRM 4361B) / (SRM 4926E / SRM 4926C), using the massic-activity ratios given in Table 3 . 
Using the NIST length-compensated internal gas proportional counters, the massic activity of SRM 4927E was determined to be $370060 \mathrm{~Bq} \cdot \mathrm{g}^{-1}$ as of $1200 \mathrm{EST}$, 3 September 1998, with a relative expanded uncertainty (coverage factor $k=2$ ) of $0.70 \%$ [4]. Using the massic activity value for SRM 4927E and the massic-activity ratios in the tables, one can calculate the massic activity of any of the other SRMs (except SRMs 4927C and 4927D). Where a different reference time is desired for the massic activity, the recommended half-life is $(4500 \pm 8) \mathrm{d}$, where $8 \mathrm{~d}$ corresponds to one standard uncertainty [5].

\section{References}

[1] W. B. Mann and H. H. Seliger, The Preparation, Maintenance and Applications of Standards of Radioactivity, National Bureau of Standards Circular No. 594, 1958.

[2] W. B. Mann, R. W. Medlock, and O. Yura, A Recalibration of the National Bureau of Standards Tritiated-water Standards by Gas Counting, Int. J. Appl. Radiat. Isot. 15, 351-361 (1963).

[3] M. P. Unterweger, B. M. Coursey, F. J. Schima, and W. B. Mann, Preparation and Calibration of the 1978 National Bureau of Standards Tritiated-water Standards, Int. J. Appl. Radiat. Isot. 31, 611-614 (1980).

[4] M. P. Unterweger and L. L. Lucas, Calibration of the National Institute of Standards and Technology Tritiated-water Standards, Appl. Radiat. Isot. 52, 527-531 (2000).

[5] L. L. Lucas and M. P. Unterweger, Comprehensive Review and Critical Evaluation of the Half-Life of Tritium, J. Res. Natl. Inst. Stand. Technol. 105, 541-549 (2000).

About the author: Larry Lucas is a Research Chemist in the Ionizing Radiation Division of the NIST Physics Laboratory. The National Institute of Standards and Technology is an agency of the Technology Administration, U.S. Department of Commerce. 